\title{
Can crop albedo be increased through the modification of leaf trichomes, and could this cool regional climate?
}

\author{
A letter \\ Christopher E. Doughty • Christopher B. Field • \\ Andrew M. S. McMillan
}

Received: 11 June 2010 / Accepted: 28 August 2010 / Published online: 4 November 2010

(C) The Author(s) 2010. This article is published with open access at Springerlink.com

\begin{abstract}
Managing the land surface to increase albedo to offset regional warming has received less attention than managing the land surface to sequester carbon. We test whether increasing agricultural albedo can cool regional climate. We first used the Community Atmosphere Model (CAM 3.0) coupled to the Community Land Model (CLM 3.0) to assess the broad climatic effects of a hypothetical implementation of a strategy in which the albedo of cropland regions is increased using high albedo crops. Simulations indicate that planting brighter crops can decrease summertime maximum daily $2 \mathrm{~m}$ air temperature by $0.25^{\circ} \mathrm{C}$ per 0.01 increase in surface albedo at high latitudes $\left(>30^{\circ}\right)$. However, planting brighter crops at low latitudes $\left(<30^{\circ}\right)$ may have negative repercussions including warming the land surface and decreasing precipitation, because increasing the land surface albedo tends to preferentially decrease latent heat fluxes to the atmosphere, which decreases cloud cover and rainfall. We then test a possible method for increasing crop albedo by measuring the range of albedo within 16 isolines of soybeans that differ only with trichome color, orientation, and density but find that such modifications had only minor impacts on leaf albedo. Increasing agricultural albedo may cool high latitude regional climate, but increasing plant albedo sufficiently to offset potential future warming will require larger changes to plant albedo than are currently available.
\end{abstract}

Electronic supplementary material The online version of this article (doi:10.1007/s10584-010-9936-0) contains supplementary material, which is available to authorized users.

C. E. Doughty $(\varangle) \cdot$ C. B. Field

Department of Global Ecology, Carnegie Institution, Stanford, CA 94305, USA

e-mail: chris.doughty@ouce.ox.ac.uk

A. M. S. McMillan

National Institute of Water \& Atmospheric Research Ltd., Wellington, New Zealand 


\section{Introduction}

The management of terrestrial land surfaces for climate change mitigation has focused mainly on the exchange of greenhouse gases, yet climate forcing due to surface albedo changes can be equally important on regional scales (Betts 2007). Modeling studies have suggested that the radiative impact of land use change can be driven more by changes in surface albedo than by changes in greenhouse gas exchange (Bala et al. 2007). In boreal forests, cooling caused by the increased albedo of the new vegetation that follows wildfire exceeds the warming caused by greenhouse gas emissions from the fire and the reduced $\mathrm{CO}_{2}$ uptake rates that occur during early succession (Randerson et al. 2006). Strategies to cool air temperatures by increasing the planetary albedo have been proposed, and include such approaches as injecting reflective aerosols into the stratosphere (Crutzen 2006; Wigley 2006), or deploying space-borne orbital sunshades (Angel 2003). These global albedo manipulations, or geo-engineering proposals, have been criticized as expensive and risky (Brewer 2007). Albedo-induced cooling at smaller scales might be achieved, instead, through deliberate management of the albedo at the land surface as had been demonstrated in a previous modeling study (Ridgwell et al. 2009).

There are several currently available possibilities for modifying the albedo of the land surface, including changes in choice of crop type, crop phenology and timing of practices, increasing the albedo of roofs and pavement, and conversion of coniferous forest plantations to broad-leaf deciduous. Additional strategies that could be developed in the future could include modifications of plant morphology such as modifying leaf characteristics to increase leaf pubescence, surface waxes, or canopy architecture to maximize albedo.

Plants adapted to arid, hot zones have distinctive features to reflect excess solar energy, especially in the near infrared (NIR), which is not used for photosynthesis (Gates et al. 1965). A desert shrub, Encelia farinosa, has exceptionally bright leaves due to a thick layer of hairs that scatter preferentially in the NIR (700-3,000 nm) (Ehleringer and Bjorkman 1978). Other plants have developed reflective leaf hairs on the underside of leaves that can increase leaf level NIR albedo by $\sim 0.1$ (Eller and Willi 1977). Agricultural scientists have modified crop morphology with concomitant increases in albedo. Leaf pubescence in soybeans was increased fourfold over normal varieties to increase crop water use efficiency (Baldocchi et al. 1983), thereby increasing surface albedo by $\sim 0.01$ (Nielsen et al. 1984). Switching from a potential biofuel crop such as corn (albedo: $0.20-0.23$ ) or soybean (albedo: 0.21 ) to a higher albedo potential biofuel crop, such as sunflower (albedo: 0.24-0.30) can increase surface albedo by $\sim 0.06$ (Breuer et al. 2003).

Globally, if all agricultural areas planted crops with a higher albedo, much of the Earth's terrestrial surface would absorb less energy and potentially cool regional air temperatures. This paper has 2 goals: (1) we assess the climate implications of a theoretical implementation of a worldwide increase in agricultural albedo and (2) we test one such method, modifying soybean trichome density, color, and orientation. We ask the following questions:

1. What are the temperature implications and other climate feedbacks of a hypothetical increase in crop albedo?

2. Does crop albedo change with the modification of trichome density, color or orientation? 


\section{Methods}

2.1 Climate simulations: testing the climatic effects of a global agricultural albedo manipulation

We used NCAR's Community Atmosphere Model (CAM 3.0; http://www.ccsm.ucar. edu/models/atm-cam/) (Collins et al. 2006), coupled with the Community Land Model (CLM 3.0; http://www.cgd.ucar.edu/tss/clm/) and a slab ocean model. The simulations were run at a 20 min time step with a resolution of $2^{\circ}$ by $2.5^{\circ}$ at the equator for 60 years, with no dynamic vegetation response and atmospheric $\mathrm{CO}_{2}$ held constant at $370 \mathrm{ppm}$. Results were calculated as the average of the final 30 years.

We simulated global climate under scenarios where leaf level reflectance for all crops worldwide was increased by $0.05,0.10,0.15$ in both the visible (control = 0.11 ) and the NIR (control $=0.58$ ). We did not modify leaf level transmittance (0.07 visible, $0.25 \mathrm{NIR}$ ) or other inputs such as canopy architecture (Dorman and Sellers 1989). The surface albedo was calculated using a two-stream radiation transfer model (Dickinson 1983). We calculated surface albedo as the ratio of direct reflected to direct beam incident solar radiation for agricultural grid cells (grid cells where agriculture has the largest percentage land cover of the four land use types given). A comparison of leaf level albedo to total grid cell albedo is in the supplementary material (SM Fig. 1). Twenty-four hour averaged changes in surface albedo were similar to changes in local noon albedo. Most agricultural grid cells also contained smaller percentages of other land use types. Changes in shortwave direct albedo for the agriculture component of each grid cell were calculated as the change in shortwave direct albedo for the entire pixel multiplied by the fraction of agriculture in each grid cell.

\subsection{Field studies: measuring transmittance and reflectance of soybean isolines with different trichome characteristics}

We obtained seeds for 16 varieties of soybeans from the USDA's national soybean research center. These soybeans were isolines that differed only in trichome density (glabrous, sparse, normal, and dense), color (grey and tawny), and leaf hair orientation (erect, appressed, and curly). We grew four individual plants of each variety in a controlled environment greenhouse. Plants were watered daily, light was controlled at $16 \mathrm{~h}$ of, at a minimum, $1,000 \mu \mathrm{mol} \mathrm{m} \mathrm{m}^{-2} \mathrm{~s}^{-1}$, and temperature was controlled at $28^{\circ} \mathrm{C}$.

We measured hemispherical reflectance and transmittance for wavelengths between 400 and $1600 \mathrm{~nm}$ for each leaf using a full range spectrometer with $10 \mathrm{~nm}$ sampling (Analytical Spectra devices, Inc. Boulder, CO USA), a Li-Cor integrating sphere (Li-Cor Biosciences, Lincoln, NE), and an illumination collimator. The spectra were then calibrated for dark current and stray light and referenced to a calibration block (Spectralon, Labsphere Inc. Durham, NH) within the integrating sphere. We made four to five measurements of reflectance and transmittance on the healthiest looking leaves for each isoline and determined significance using a paired Student's $t$ test. We assessed differences among isolines using multivariate ANOVA (Matlab Statistical Toolbox, MathWorks Inc., Natick, MA, USA) 


\section{Results}

\subsection{Climate simulations}

To understand the sensitivity of regional temperature to a change in crop albedo, we simulated climate under scenarios where global agricultural leaf level reflectance is increased by $0.05,0.10$, and 0.15 . Regional cooling with increased agricultural albedo was not evenly distributed. There was substantial cooling in Eurasia, North America, and southern South America, but albedo-induced cooling was less frequent, and of smaller magnitude in agricultural regions at lower latitudes, including areas in India, South East Asia and southern Brazil.

Based on this geographic divergence, we considered low latitude regions (between $30^{\circ} \mathrm{N}$ and $30^{\circ} \mathrm{S}$ ) separately from high latitude regions (poleward of $30^{\circ} \mathrm{N}$ or $30^{\circ} \mathrm{S}$ ) for the rest of the study. At low latitudes, increases in leaf level reflectance of $0.05,0.10$, and 0.15 translated into an average top-of-atmosphere increase in albedo of 0.033 , $0.056,0.061$, respectively, while at high latitudes the same increases translated into an average top-of-atmosphere increase in albedo of $0.040,0.065$, and 0.077 , respectively. For each 0.01 increase in surface albedo, daily maximum temperatures in pixels that were dominated by agriculture cooled by an average of $0.25^{\circ} \mathrm{C}$ at high latitudes, and by $0.07^{\circ} \mathrm{C}$ at low latitudes during summertime (defined here as JJA in the northern hemisphere and DJF in the southern hemisphere) (Fig. 1, grey circles). For each 0.01 increase in surface albedo, daily maximum temperatures across all land surfaces

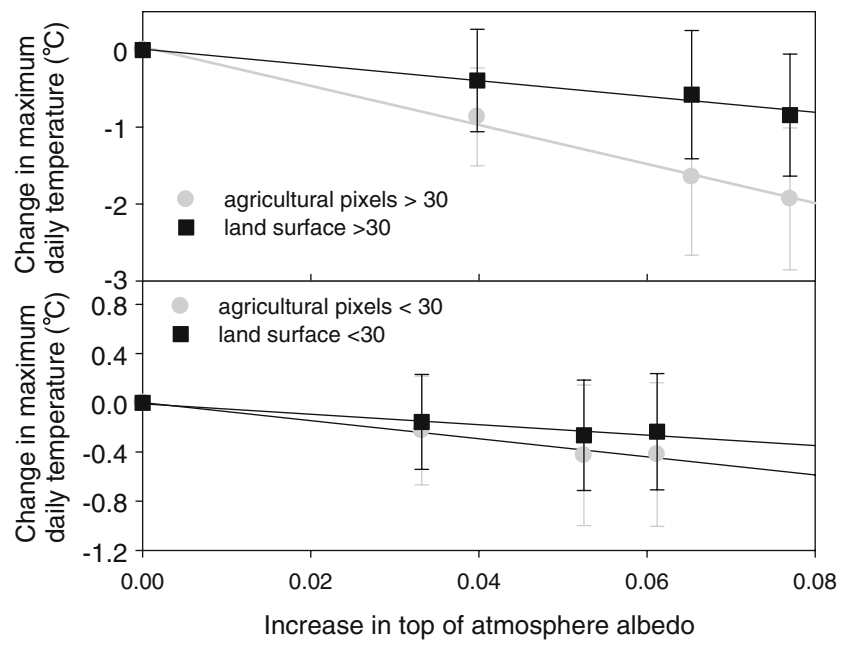

Fig. 1 Change in mean $( \pm S D)$ summertime maximum daily $2 \mathrm{~m}$ air temperature for agricultural pixels between a control simulation and simulations where we increased leaf level albedo by 0.05 , 0.10 , and 0.15 . We simulated climate for 60 years, averaging over the final 30 years and separated high latitude regions ( $>30 \mathrm{~N}$ and $\mathrm{S}$ ) from low latitude regions ( $<30 \mathrm{~N}$ and $\mathrm{S}$ ). Leaf albedo changes are identical at different latitudinal bands but top-of-atmosphere albedos vary because they include cloud albedo feedbacks 
cooled by an average of $0.10^{\circ} \mathrm{C}$ at high latitudes, and by $0.04^{\circ} \mathrm{C}$ at low latitudes during summertime (Fig. 1, black squares).

Low-latitude rainfall decreased at a rate of $0.66 \mathrm{~mm} \mathrm{month}{ }^{-1}$ for each 0.01 increase in surface albedo but there was no significant change in rainfall at high latitudes with increased albedo (Fig. 2). At high latitudes, sensible heat decreased by $0.54 \mathrm{~W} \mathrm{~m}^{-2}$ and latent heat decreased by $0.19 \mathrm{~W} \mathrm{~m}^{-2}$ for each 0.01 increase in surface albedo. At low latitudes, sensible heat decreased by $0.22 \mathrm{~W} \mathrm{~m}^{-2}$ and latent heat decreased by $0.38 \mathrm{~W} \mathrm{~m}^{-2}$ for each 0.01 increase in surface albedo. High latitude cloud cover increased by 0.0012 for each 0.01 increase in surface albedo and low latitude cloud cover decreased by 0.0005 for each 0.01 increase in surface albedo.

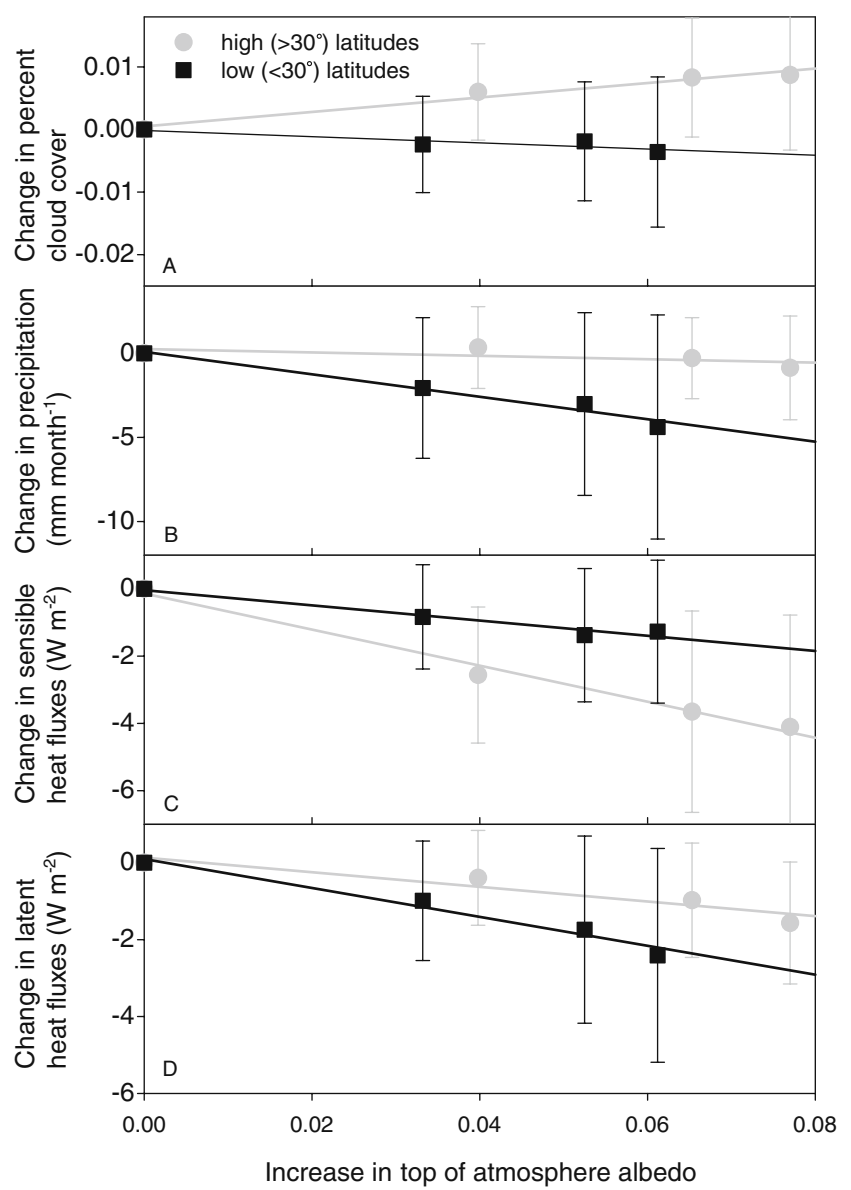

Fig. 2 Change in annual mean $( \pm S D)$ percent cloud cover (a), precipitation (b), latent heat fluxes (c), and sensible heat fluxes (d) for agricultural pixels between a control simulation and simulations where we increased leaf level albedo by $0.05,0.10$, and 0.15 . We simulated climate for 60 years, averaging over the final 30 years and separated high latitude regions ( $>30 \mathrm{~N}$ and $\mathrm{S}$ ) from low latitude regions $(<30 \mathrm{~N}$ and $\mathrm{S})$. Leaf albedo changes are identical at different latitudinal bands but top-ofatmosphere albedos vary because they include cloud albedo feedbacks 


\subsection{Leaf level albedo}

We compared leaf level reflectance and transmittance for glabrous isolines of soybeans $(\mathrm{N}=10)$ to all soybean isolines with trichomes $(\mathrm{N}=65)$ (Fig. 3). Soybeans with trichomes reflected incident radiation more effectively than glabrous soybeans: There was no significant change in reflectance in the visible $(400-700 \mathrm{~nm})$, a significant increase in reflectance of 0.023 in the NIR $(700-1,400 \mathrm{~nm})$ and a 0.005 increase above $1400 \mathrm{~nm}$ (Fig. 3). However, soybeans with trichomes transmitted incident radiation less effectively than glabrous soybeans: There was a significant $(P<0.05) 0.023$ decrease in transmittance in the visible $(400-700 \mathrm{~nm})$, a significant decrease of 0.034 in the NIR ( 700 and $1400 \mathrm{~nm}$ ) and a 0.055 significant increase above $1400 \mathrm{~nm}$ (Fig. 3). Overall, soybeans with trichomes absorbed more incident radiation than glabrous soybeans. There was a significant $(P<0.05) 0.02$ increase in absorption in the visible (400-700 nm), no significant change in the NIR (700 and $1400 \mathrm{~nm})$, and a 0.068 significant $(P<0.05)$ increase at higher wavelengths $(>1,400 \mathrm{~nm})$.

We assessed how individual trichome characteristics affected absorption by comparing isolines that differed in color, orientation and density of trichomes (Table 1$)$. Isolines with curly trichomes reflected significantly more $(P<0.05)$ incident radiation in the visible than isolines with erect or appressed trichomes. Isolines with tawny trichomes reflected significantly more $(P<0.05)$ incident radiation in the NIR and IR than isolines with grey trichomes (Table 1). Isolines with a sparse trichome density did not reflect significantly more $(P>0.05)$ incident radiation than isolines with a dense trichome density. None of the significant differences in albedo between trichome isolines were greater than 0.01 .

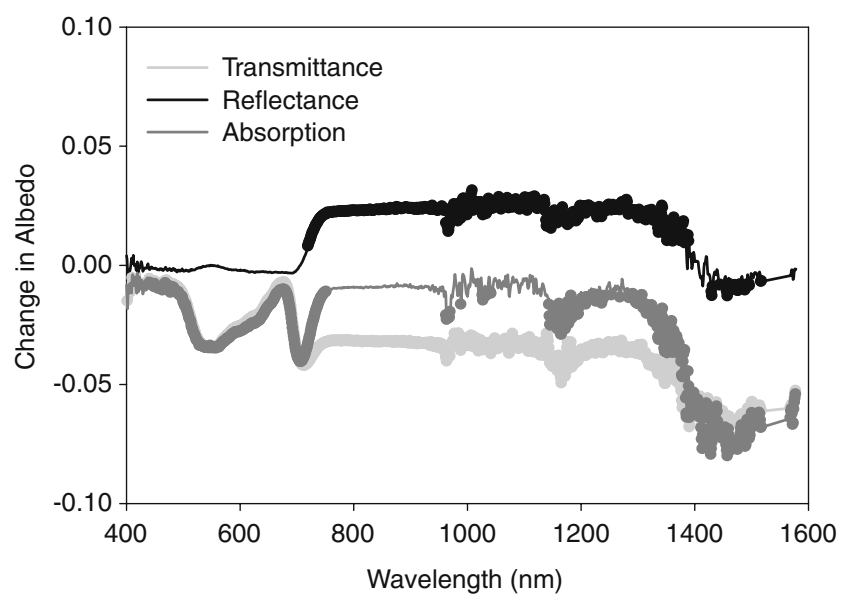

Fig. 3 The change in transmittance (grey), reflectance (black) and absorption (dark grey) between glabrous soybeans $(N=10)$ and a combination of all 15 isolines of soybeans with trichomes $(N=$ 65). Increases or decreases in a particular parameter are reported as arithmetic differences between treatments. Wavelength regions in which significant differences occurred are represented by the thicker lines (Student's $t$ test, $P<0.05$ ). A negative change in absorption indicates fewer photons absorbed by the glabrous isolines versus isolines with trichomes 
Table 1 Average (bold) \pm SD (italics) of leaf reflectance for different trichome characteristics in the visible (400-700 nm), NIR (700-1,400 nm), and IR (1,400-1,600 nm)

\begin{tabular}{|c|c|c|c|c|c|c|c|c|}
\hline & \multicolumn{2}{|l|}{ Color } & \multicolumn{3}{|l|}{ Orientation } & \multicolumn{3}{|l|}{ Density } \\
\hline & Grey & Tawny & Appressed & Curly & Erect & Sparse & Normal & Dense \\
\hline Visible $(400-700 \mathrm{~nm})$ & 0.076 & 0.075 & $0.077^{*}$ & 0.079* & $0.072 *$ & 0.077 & 0.074 & 0.076 \\
\hline reflectance & 0.007 & 0.005 & 0.005 & 0.005 & 0.005 & 0.005 & 0.006 & 0.006 \\
\hline NIR $(700-1,400 \mathrm{~nm})$ & 0.44* & $\mathbf{0 . 4 5}^{*}$ & $\mathbf{0 . 4 5}$ & 0.45 & $\mathbf{0 . 4 4}$ & $\mathbf{0 . 4 5}$ & 0.45 & 0.44 \\
\hline reflectance & 0.01 & 0.008 & 0.005 & 0.01 & 0.013 & & & 0.01 \\
\hline $\begin{array}{l}\text { IR }(1,400-1,600 \mathrm{~nm}) \\
\text { reflectance }\end{array}$ & $\begin{array}{r}\mathbf{0 . 2 6 5}^{*} \\
0.008\end{array}$ & $\begin{array}{r}\mathbf{0 . 2 7 4} * \\
0.01\end{array}$ & $\begin{aligned} \mathbf{0 . 2 7} \\
0.015\end{aligned}$ & $\begin{array}{l}\mathbf{0 . 2 7} \\
0.005\end{array}$ & $\begin{array}{l}\mathbf{0 . 2 7} \\
0.008\end{array}$ & $\begin{array}{l}\mathbf{0 . 2 7} \\
0.012\end{array}$ & $\begin{array}{l}\mathbf{0 . 2 7} \\
0.012\end{array}$ & $\begin{array}{l}\mathbf{0 . 2 7} \\
0.006\end{array}$ \\
\hline
\end{tabular}

For statistical analysis, we used multivariate ANOVA. An asterisk indicates a significant difference $(P<0.05)$ between the means with the asterisk

\section{Discussion}

4.1 What are the temperature and other climate implications of an increase in crop albedo?

Simulations indicate that increasing albedo in agricultural regions would lead to greater cooling at high latitudes $\left(>30^{\circ}\right)$ versus low latitudes $\left(<30^{\circ}\right)$. As more shortwave energy was reflected rather than absorbed by the crops, less energy was available for sensible and latent heat. Reductions in these pathways of energy were not partitioned equally with latitude. In low latitude regions, increased albedo disproportionately decreased latent heat flux, while in high latitude regions increased albedo disproportionately decreased sensible heat flux.

Reduction in latent heat exchange was correlated with reductions in cloud cover. The reduced cloud cover at low latitudes allowed more incident solar radiation to reach the surface, resulting in increases in the net energy absorbed by the surface. The change in energy absorbed by the surface was tightly correlated to the change in surface temperature. The change in energy partitioning between high latitude $\left(>30^{\circ}\right)$ and low latitude $\left(<30^{\circ}\right)$ agricultural systems is possibly a consequence of meridional variation in the Bowen ratio (sensible heat divided by latent heat). At high latitudes, where the Bowen ratio is greater, decreases in absorbed radiation lead to decreases in sensible heat. At low latitudes, where the Bowen ratio is less, decreases in absorbed radiation lead to decreases in latent heat. In the latter case, the reduced latent heat fluxes inhibited cloud formation.

This study found that at lower latitudes, agricultural albedo manipulation may interfere with cloud formation and precipitation, and may therefore be an inappropriate strategy in these regions; a result also found using a different climate model by Ridgwell et al. (2009). Nonetheless, we believe that agricultural albedo manipulation deserves consideration as an interim strategy to offset high temperatures in certain agricultural regions, while other mitigation initiatives are implemented. Agricultural albedo manipulation is inherently reversible as crops are replanted on an annual basis.

Most agriculture occurs within middle to high latitude continental interiors where temperature increases due to global warming are expected to be large. Agricultural yield is susceptible to climate change, and temperature increases are predicted to 
cause yield declines in many areas (Lobell et al. 2008). In these regions, agricultural albedo manipulation possibly could reduce declines in crop yield caused by heat stress. Deliberate albedo manipulation may therefore achieve two complementary and related objectives: first, to induce surface temperature cooling and offset temperature increases associated with global climate change; and second, induce leaflevel cooling, thereby providing a measure of protection against temperatures that exceed the optimum range for a particular crop species. The development of new heat-tolerant cultivars is one avenue of climate change adaptation for agriculture (Rosenzweig and Parry 1994). The development of crops with high albedos may be an alternative avenue to achieve agricultural systems that maintain productivity with future temperature increases.

However, achieving increases in albedo large enough to offset increased temperatures will be difficult as was demonstrated by our effort to measure the range of albedo within soybean isolines. We found only minor differences between isolines of soybeans (Table 1) with the largest leading to a surface albedo change of $\sim 0.016$ (Supplemental material). If our linear relationships between land surface temperatures and albedo are correct, we would predict a decrease in maximum daily summertime temperatures of $\sim 0.40^{\circ} \mathrm{C}$ if crops with trichomes were replaced with crops without trichomes in high latitude agricultural regions. This would not be sufficient to counteract expected increases in global temperatures.

Our modeling studies demonstrate that increasing plant albedo may be an effective regional cooling technique in high latitude regions and therefore potentially worthy of the attention of crop breeders. However, our empirical results demonstrate that the range of albedo within current soybean isolines is not sufficient. It is clearly possibly to make brighter plants as Encelia farinosa demonstrates (Ehleringer and Bjorkman 1978). Efforts among crop breeders should focus on creating plants with air-filled, Encelia type trichomes that reflect preferentially in the NIR. However, if such plants could be developed, caution should still be exercised, because in certain global regions they could decrease latent heat fluxes to the atmosphere leading to negative effects on cloud formation and precipitation.

Acknowledgements We thank Mike Goulden, Jim Randerson, and Charlie Zender for comments. This work was funded by a Carnegie Fellowship and the Gary Comer Science and Educational Foundation.

Open Access This article is distributed under the terms of the Creative Commons Attribution Noncommercial License which permits any noncommercial use, distribution, and reproduction in any medium, provided the original author(s) and source are credited.

\section{References}

Angel R (2003) Feasibility of cooling the earth with a cloud of small spacecraft near the inner lagrange point (L1). Proc Natl Acad Sci 103:17184-17189

Bala G, Caldeira K, Wickett M, Phillips TJ, Lobell DB, Delire C, Mirin A (2007) Combined climate and carbon-cycle effects of large-scale deforestation. Proc Natl Acad Sci USA 104:9911 (vol 104,pg 6550, 2007)

Baldocchi DD, Verma SB, Rosenberg NJ, Blad BL, Garay A, Specht JE (1983) Leaf pubescence effects on the mass and energy exchange between soybean canopies and the atmosphere. Agron J 75:537-543 
Betts R (2007) Implications of land ecosystem-atmosphere interactions for strategies for climate change adaptation and mitigation. Tellus B 59:602-615

Breuer L, Eckhardt K, Frede HG (2003) Plant parameter values for models in temperate climates. Ecol Model 169:237-293

Brewer PG (2007) Evaluating a technological fix for climate. Proc Natl Acad Sci USA 104:9915-9916

Collins WD, Bitz CM, Blackmon ML, Bonan GB, Bretherton CS, Carton JA, Chang P, Doney SC, Hack JJ, Henderson TB, Kiehl JT, Large WG, McKenna DS, Santer BD, Smith RD (2006) The community climate system model version 3 (CCSM3). J Climate 19:2122-2143

Crutzen PJ (2006) Albedo enhancement by stratospheric sulfur injections: a contribution to resolve a policy dilemma. Clim Change 77:211-219

Dickinson RE (1983) Land surface processes and climate surface albedos and energy-balance. Adv Geophys 25:305-353

Dorman JL, Sellers PJ (1989) A global climatology of albedo, roughness length and stomatalresistance for atmospheric general-circulation models as represented by the simple biosphere model (Sib). J Appl Meteorol 28:833-855

Ehleringer JR, Bjorkman O (1978) Comparison of photosynthetic characteristics of encelia species possessing glabrous and pubescent leaves. Plant Physiol 62:185-190

Eller BM, Willi P (1977) Significance of leaf pubescence for absorption of global radiation by tussilago-farfara L'. Oecologia 29:179-187

Gates DM, Keegan HJ, Schleter JC, Weidner VR (1965) Spectral properties of plants. Appl Optics 4:11

Lobell DB, Burke MB, Tebaldi C, Mastrandrea MD, Falcon WP, Naylor RL (2008) Prioritizing climate change adaptation needs for food security in 2030. Science 319:607-610

Nielsen DC, Blad BL, Verma SB, Rosenberg NJ, Specht JE (1984) Influence of soybean pubescence type on radiation balance. Agron J 76:924-929

Randerson JT, Liu H, Flanner MG, Chambers SD, Jin Y, Hess PG, Pfister G, Mack MC, Treseder KK, Welp LR, Chapin FS, Harden JW, Goulden ML, Lyons E, Neff JC, Schuur EAG, Zender CS (2006) The impact of boreal forest fire on climate warming. Science 314:1130-1132

Ridgwell A, Singarayer JS, Hetherington AM, Valdes PJ (2009) Tackling regional climate change by leaf albedo bio-geoengineering. Curr Biol 19:146-150

Rosenzweig C, Parry ML (1994) Potential impact of climate-change on world food-supply. Nature 367:133-138

Wigley TML (2006) A combined mitigation/geoengineering approach to climate stabilization. Science 314:452-454 